\title{
Avaliação do ciclo de vida e apoio à decisão em gerenciamento integrado e sustentável de resíduos sólidos urbanos
}

\author{
Life cycle assessment and decision making support in integrated \\ and sustainable municipal solid waste management
}

Geraldo Antônio Reichert'1, Carlos André Bulhões Mendes²

\section{RESUMO}

O estudo da participação de diferentes atores sociais por meio de técnicas estruturadas de apoio à decisão na montagem de cenários ou alternativas futuras de coleta e tratamento de resíduos sólidos urbanos foi aplicado ao município de Porto Alegre, Rio Grande do Sul. Utilizando a ferramenta de avaliação de ciclo de vida foram avaliados oito cenários distintos, montados com a participação dos atores sociais e técnicos municipais. Diferentes alternativas de coleta (seletiva e conteinerizada) e de tratamento (reciclagem, compostagem, digestão anaeróbia, processos térmicos e disposição em aterro) foram consideradas. Conclui-se que a aplicação da avaliação de ciclo de vida facilita o apoio à decisão em sistemas municipais de gestão de resíduos sólidos urbanos, sendo que, no caso em estudo, o cenário mais sustentável foi construído pelos atores vinculados diretamente ao órgão municipal de gestão de resíduos.

Palavras-chave: sustentabilidade; gerenciamento; resíduos sólidos; atores sociais; Porto Alegre; IWM-2; avaliação do ciclo de vida (ACV).

\begin{abstract}
The study of the participation of different stakeholders through structured techniques to support decision making in building future alternatives or scenarios for the collection and treatment of municipal solid waste was applied to the city of Porto Alegre, Rio Grande do Sul, Brazil. Using the life cycle assessment tool, eight different scenarios, constructed with the participation of social stakeholders and municipal technicians, were evaluated. Different collection alternatives (selective and containerized) and treatment (recycling, composting, anaerobic digestion, thermal processes and landfill disposal) were considered. We conclude that the application of the life cycle assessment tool facilitates decision-making support systems in municipal solid waste management. In our case study, the most sustainable scenario was built by municipal waste management stakeholders.
\end{abstract}

Keywords: sustainability; management; solid waste; stakeholders; Porto Alegre; IWM-2; life cycle assessment (LCA).

\section{INTRODUÇÃO}

O correto gerenciamento dos resíduos sólidos é um dos principais desafios dos grandes centros urbanos no início deste novo milênio. Até bem pouco tempo atrás, no Brasil e na América Latina, as ações no campo dos resíduos sólidos se restringiam à limpeza urbana, ficando o tratamento e a disposição final dos resíduos completamente relegados. Ao longo das últimas duas décadas, várias ações e projetos têm sido propostos para a melhoria da disposição final e o tratamento dos resíduos sólidos urbanos (RSU). Dados da Pesquisa Nacional Saneamento Básico (PNSB) apontam uma evolução de 1,1\%, em 1989, para 27,7\% dos municípios do Brasil, em 2008, que dispõem seus resíduos de forma correta em aterros sanitários (IBGE, 2010). O problema da disposição inadequada ainda permanece, principalmente nos pequenos municípios. Ainda, segundo a mesma pesquisa, somente $18 \%$ dos municípios têm algum programa de coleta seletiva, e o índice de compostagem é da ordem de, apenas, $1 \%$.

Muitas das soluções que têm sido propostas trazem em si o equívoco da autossuficiência. São soluções isoladas e estanques, que não contemplam a questão dos resíduos do momento de sua geração até a disposição final, passando pelo seu tratamento. Estas "soluções", mesmo sendo boas em princípio, não conseguem resolver o problema como um todo.

'Engenheiro Civil. Doutor em Recursos Hídricos e Saneamento Ambiental pela Universidade Federal do Rio Grande do Sul (UFRGS) - Porto Alegre (RS), Brasil. Professor Adjunto da Universidade de Caxias do Sul (UCS) - Caxias do Sul (RS), Brasil.

²Engenheiro Civil. Doutor em Planejamento Ambiental pela Universidade de Bristol - Bristol, Inglaterra. Pós Doutorado pela Universidade da Califórnia - Berkeley (Califórnia), EUA. Professor Adjunto do Instituo de Pesquisas Hidráulicas (IPH) da UFRGS - Porto Alegre (RS), Brasil.

Endereço para correspondência: Geraldo Antônio Reichert-Avenida da Azenha, 631 - 90160-001 - Porto Alegre (RS), Brasil - E-mail: gareichert@cpovo.net Recebido: 18/07/13 - Aceito: 05/02/14 - Reg. ABES: 1145 
As soluções mundialmente mais adotadas se baseiam no gerenciamento integrado dos resíduos sólidos. Não está claro ainda, entretanto, como um sistema municipal de gerenciamento de resíduos sólidos pode ser desenvolvido de modo que seja integrado e sustentável. Segundo White et al. (1995), gerenciamento integrado e sustentável de resíduos sólidos é uma forma diferenciada de manejo de resíduos, que combina diferentes métodos de coleta e tratamento para lidar com todos os materiais no fluxo de geração e descarte de resíduos, de maneira ambientalmente efetiva, economicamente viável e socialmente aceitável.

Wilson et al. (2001) avaliaram os sistemas de manejo de resíduos de 11 diferentes programas-líder de gerenciamento municipal na Comunidade Europeia, em nove diferentes países. Nessa avaliação, os aspectos econômico, social, político, ambiental, legal e técnico de cada programa específico foram explorados e analisados. Umas das principais conclusões desse estudo é que, em função do grande número de variáveis envolvidas e das diferentes questões intrínsecas a cada município, não há "um modo correto" para manejar os resíduos ou para criar um sistema integrado de gerenciamento. Mas há metodologias de como chegar ao melhor modo de fazê-lo, por isso, cada municipalidade deverá buscar o desenvolvimento de seu próprio modelo ou sistema, baseado nas características e peculiaridades locais.

No gerenciamento dos resíduos urbanos, faz-se necessário uma mudança de paradigma e a busca de novos modelos, deixando de identificar os administradores públicos como simples gestores de resíduos, e passando-os a gestores de recursos, seja esse o composto, materiais para geração de energia ou calor, recuperação de materiais para (re) produção de bens de consumo, etc., sendo o resíduo sólido final apenas mais um material a ser gerenciado (Kuhn, 2003).

Para a definição dos sistemas sustentáveis de manejo de resíduos, a montagem de cenários com diferentes opções de coleta, de tratamento e de disposição final tem sido utilizada. Cenários de gerenciamento de resíduos são as possíveis diferentes alternativas de manejo dos resíduos, que podem incluir as etapas de coleta, transporte, triagem centralizada, reciclagem de materiais, tratamento biológico, tratamento térmico e aterro sanitário. O que se busca é uma combinação dessas diferentes técnicas e tecnologias que resulte no sistema mais ambientalmente efetivo em termos de emissões gasosas, líquidas e de resíduo sólido final, em um custo mais viável e que seja socialmente aceitável pela população.

A limpeza urbana e o gerenciamento dos resíduos sólidos municipais correspondem a uma fatia que varia de 5 a $15 \%$ dos orçamentos públicos dos municípios (IPES \& BID, 2005). O planejamento sistemático do setor de resíduos sólidos por parte do poder público se torna ainda mais relevante com a aprovação da Lei Federal 12.305/2010, que institui a Política Nacional de Resíduos Sólidos (BRASIL, 2010). Essa lei estabelece a priorização da reciclagem e do tratamento dos resíduos (com a obrigatoriedade dos municípios estabelecerem metas de reciclagem e de redução de envio para aterro sanitário), destinando para aterros sanitários somente aqueles resíduos que não podem ser reaproveitados, os chamados rejeitos, bem como comprovação da viabilidade técnica e ambiental de tecnologias de recuperação enérgica de resíduos.

Fica explícita, pelo estabelecido pela política de resíduos sólidos, a importância do estabelecimento de metodologias aplicáveis à realidade brasileira e que atendam aos princípios e objetivos dessa política, em especial a visão sistêmica da gestão dos resíduos, a sustentabilidade e o direito da sociedade à informação e ao controle social.

Por fim, é de fundamental importância a participação social na definição do sistema de gerenciamento a ser adotado em determinado município, pois conforme afirmam Joos et al. (1999), um sistema ou programa de gerenciamento de resíduos que ignora os aspectos sociais está fadado ao fracasso. Daí a relevância do estabelecimento de um procedimento metodológico que incorpore os atores sociais no processo de tomada de decisão.

Nessa busca por novas formulações de sistemas de gerenciamento de resíduos, a questão que se coloca é: "a participação social na definição de modelos de gerenciamento integrado de resíduos sólidos urbanos resulta em um sistema mais sustentável do que modelos desenvolvidos somente com a participação de técnicos especialistas?” É justamente essa questão que se pretende responder neste trabalho.

\section{METODOLOGIA}

A metodologia geral adotada nesta pesquisa foi dividida em seis módulos, conforme descrito a seguir. No Módulo 1 foram definidos os atores sociais que participam da pesquisa e da definição do modelo de apoio à tomada de decisão, fazendo a divisão dos atores sociais em dois grupos, os especialistas no órgão municipal de RSU e os especialistas convidados (chamados de outros atores sociais) ligados diretamente ou indiretamente à gestão de resíduos sólidos e questões ambientais, mas não pertencentes ao órgão municipal de resíduos sólidos.

No Módulo 2, a partir da montagem, pelo autor, de um cenário Base, os atores sociais sugeriram a montagem de outros cenários de gerenciamento de RSU para o município de Porto Alegre.

No Módulo 3 foi feita a aplicação da ferramenta de inventário de ciclo de vida (ICV) por meio da utilização do programa computacional IWM-2 (McDougall et al., 2001), resultando no inventário de energia utilizada e da emissão de efluentes (sólidos, líquidos e gasosos), bem como a produção de energia útil e materiais recicláveis.

A Avaliação dos Impactos de Ciclo de Vida (AICV) foi feita no Módulo 4, com a utilização de indicadores de sustentabilidade ambiental, econômica e social.

No Módulo 5 foi feita a consolidação final de todos os resultados da AICV dos cenários avaliados, fazendo a hierarquização final dos cenários segundo o índice de sustentabilidade geral obtido a partir dos indicadores avaliados e comparando com a hierarquização feita no Módulo 2 pelos diferentes grupos de atores sociais. 
Por fim, no Módulo 6, foi verificada a hipótese da pesquisa, de que a participação de diferentes atores sociais resulta em cenários de gerenciamento de RSU mais sustentáveis do que os cenários definidos somente por especialistas do setor municipal de gerenciamento de RSU.

A participação dos atores sociais se deu através da aplicação de questionários enviados e recebidos via correio eletrônico. A metodologia de AICV utilizada considera as três partes da sustentabilidade de sistemas, as sustentabilidades ambiental, econômica e social, e foi adaptada da metodologia CML 2001 de Guinéé et al. (2001), modificada e adaptada para resíduos sólidos urbanos por Den Boer et al. (2005a,b,c), e está descrita a seguir.

\section{Sustentabilidade ambiental}

A etapa de AICV consiste na aplicação de uma metodologia para estabelecer uma conexão entre o inventário e os danos ou impactos potenciais, como "mudanças climáticas" ou "toxicidade humana". Os resultados obtidos na etapa do inventário, feito com utilização do programa IWM-2, foram agregados ao longo de todo o ciclo de vida do sistema. Multiplicando resultados simples de emissões e uso de recursos por fatores de caracterização, esses foram atribuídos aos indicadores de avaliação do ciclo de vida (ACV), conforme descrito na sequência. A etapa de AICV consiste das seguintes etapas:

- Seleção das categorias de impacto: indicadores para as categorias e modelos para quantificar a contribuição das diferentes entradas e emissões para cada categoria específica de impacto. Os seguintes indicadores e categorias de impactos são utilizados neste trabalho: uso de energia, mudanças climáticas, toxicidade humana, formação de foto-oxidantes ou oxidação química, acidificação, eutrofização, disposição em aterro de materiais recicláveis secos e disposição em aterro de materiais recicláveis orgânicos;

- Classificação: alocação dos resultados do inventário às categorias de impacto. A classificação e a etapa seguinte de caracterização foram feitas adotando a metodologia CML 2001 descrita por Den Boer et al. (2005b);

- Caracterização: são realizados cálculos para avaliar a significância relativa de cada fator contribuinte ao impacto global do sistema em estudo, convertendo-os em um indicador comum.

A classificação dos distintos poluentes de acordo com as categorias de impacto, bem como os fatores de caracterização de cada um destes poluentes emitidos foi realizada com base nos valores apontados por Den Boer et al. (2005b).

Como exemplo, tem-se a categoria de impacto "mudanças climáticas". O potencial de aquecimento global (PAG) é usado como fator de caracterização para avaliação e agregação da categoria "mudanças climáticas". O indicador geral é calculado conforme a Equação 1.
$M d C l=\sum_{i=1}^{n} P A G_{i} \times m_{i}$

onde:

$\mathrm{MdCl}$ : resultado do indicador, que é expresso em kg- $\mathrm{CO}_{2}$-equivalente; PAG $\mathrm{i}_{\mathrm{i}}$ : potencial de aquecimento global da substância $i$; $\mathrm{m}_{\mathrm{i}}$ : massa da substância $i$ emitida em kg.

De acordo com Guinée et al. (2001), contribuem para o impacto "mudanças climáticas" o dióxido de carbono, o metano e o óxido nitroso, sendo o PAG do $\mathrm{CO}_{2}=1$; do $\mathrm{CH}_{4}=23$ e do $\mathrm{N}_{2} \mathrm{O}=296 \mathrm{~kg} \mathrm{CO}_{2}$ equivalente.

As etapas opcionais, segundo a NBR ISO 14.044 (ABNT, 2009), que foram realizadas nesta pesquisa são as seguintes:

- Normalização: etapa utilizada para expressar o indicador de impacto de maneira a possibilitar a sua comparação dentre as categorias de impacto. Os valores de normalização utilizados nesta pesquisa são os apresentados na Tabela 1. Desta forma, os indicadores ambientais foram normalizados em termos de equivalentes populacionais (EP) (habitantes), conforme metodologia sugerida por Guinée et al. (2001);

- Ponderação (atribuição de pesos): etapa da AICV que consiste na atribuição de pesos ou valores relativos às diferentes categorias de impacto baseada nas suas respectivas importâncias ou relevâncias. O intervalo de variação para os fatores de ponderação a ser adotado nessa pesquisa vai de 3 (muito importante) a 0 (sem importância).

Tabela 1 - Fatores de normalização CML 2001, referência anual per capita.

\begin{tabular}{|c|c|}
\hline Categoria de impacto & Mundo, 1995 \\
\hline Mudanças climáticas ( $\mathrm{kg} \mathrm{CO}_{2}$ eq:ano-1.'cap') & 6.830 \\
\hline Toxicidade humana (kg 1,4-diclorobenzeno eqano ${ }^{-1} \cdot \mathrm{cap}^{-1}$ ) & 8.800 \\
\hline Formação de foto-oxidantes $\left(\mathrm{kg} \mathrm{C}_{2} \mathrm{H}_{4}\right.$ eq:ano $\left.{ }^{-1} \cdot \mathrm{cap}^{-1}\right)$ & 8,04 \\
\hline Acidificação (kg SO ${ }_{2}$ eq·ano'-cap $\left.{ }^{-1}\right)$ & 52,9 \\
\hline Eutrofização (kg PO $\mathrm{P}_{4}$ eq·ano-1.'cap $\left.{ }^{-1}\right)$ & 22,8 \\
\hline Uso de energia (GJ energia eqano ${ }^{-1} \cdot \mathrm{cap}^{-1}$ ) & 72,0 \\
\hline
\end{tabular}

Fonte: Adaptado de Guinée et al. (2001).

\section{Avaliação econômica}

Com base na proposição de Den Boer et al. (2005a), os critérios e indicadores econômicos descritos a seguir são aplicados neste trabalho: custo total por tonelada, por domicílio e por pessoa; custo do SGIRSU ${ }^{1}$ como percentagem do orçamento total do município; custo por pessoa como percentagem do valor do salário mínimo; e relação entre receitas e despesas do SGIRSU.

${ }^{1}$ SGIRSU - Sistema de gerenciamento integrado de resíduos sólidos urbanos. 
Para avaliação da sustentabilidade econômica dos cenários, foi realizado o levantamento de todos os custos reais atuais do sistema de gerenciamento de RSU em Porto Alegre. Esses custos foram levantados junto ao Departamento Municipal de Limpeza Urbana (DMLU) e a Prefeitura de Porto Alegre e serviram para definição dos indicadores econômicos do cenário \#1 BASE, tendo como referência o ano de 2011.

Para a avaliação econômica dos demais cenários construídos com a participação social, duas metodologias distintas foram adotadas. Para estimativa dos custos dos sistemas futuros de coleta tomou-se como base os custos unitários $(\mathrm{R} \$ / \mathrm{t}$ ) de cada tipo de coleta (convencional porta-a-porta, seletiva e conteinerizada). Com base nos tipos de coleta adotados em cada um dos cenários foi feito o cálculo proporcional do custo total da coleta naquele cenário.

Para estimativa dos custos dos sistemas de tratamento e aterro sanitário dos cenários futuros, foram utilizadas curvas de custo apresentadas por Tsilemou e Panagiotakopoulos (2005), apresentadas na Tabela 2, e referendadas por Den Boer et al. (2005a), que utilizam estas curvas no modelo de AICV LCA-IWM.

\section{Avaliação social}

Em termos gerais, a sustentabilidade social é o comportamento ético de um sistema de gerenciamento de resíduos para com a sociedade. Baseado em Den Boer et al. (2005c), os seguintes critérios e indicadores foram utilizados, sendo aplicados aos estágio de armazenamento temporário, coleta e destinação/tratamento: odor; impacto visual; uso espaço urbano; uso espaço privado; complexidade; qualidade dos empregos gerados; índice de reciclagem/disposição final; e quantidade de empregos.

A metodologia de cálculo dos indicadores sociais proposta por Den Boer et al. (2005a) e adotada nesta pesquisa é:

- Definição de possíveis valores para variáveis independentes, que são classificados em níveis, da melhor situação para a pior;

- Um valor de escala (variando 0 a 4) é atribuído a cada situação. Esse valor é definido pelo nível de sustentabilidade social atribuído antes, em que 0 significa a melhor situação e 4 a pior;

- O indicador é calculado como a média aritmética de todos os valores parametrizados (Equação 2).
Indicador $=\frac{v 1+v 2+v 3+\ldots+v_{n-1}+v_{n}}{n}$

- O indicador resultante é normalizado entre 0 e 1 . O valor 0 significa a melhor situação e 1 a pior situação. Com isso é possível condensar informação e comparar componentes de sistemas simples ou similares com um indicador (Equação 3).

Indicador $_{\text {normalizado }}=\frac{\text { Indicador }}{4}$

\section{Índices de sustentabilidade}

Os três subíndices de sustentabilidade (ambiental, econômica e social) foram calculados pela equação geral, considerando a contribuição dos respectivos indicadores (Equação 4).

$\mathrm{SI}=\sum_{i=1}^{n} \operatorname{Ind}_{\mathrm{i}} \mathrm{xp}_{\mathrm{i}}$

Onde:

SI: subíndice calculado (ambiental, econômico ou social);

Ind $_{\mathrm{i}}$ : valor calculado e normalizado (entre 0 e 1 ) do indicador $\mathrm{i}$;

$\mathrm{p}_{\mathrm{i}}$ : peso do indicador $\mathrm{i}$;

n: número de indicadores que compõem o subíndice.

Resumindo ainda mais a informação, foi construído um índice de sustentabilidade geral, permitindo assim uma hierarquização final dos cenários avaliados. Esse índice foi calculado pela média ponderada dos três subíndices (ambiental, econômico e social), sendo os pesos desta ponderação também definidos pelos atores sociais, conforme a Equação 5.

$\mathrm{ISG}=1 / 3 \sum_{i=1}^{n} \mathrm{SI}_{\mathrm{i}} \mathrm{xps}_{\mathrm{i}}$

Onde:

$I S G$ = índice de sustentabilidade geral;

$S I_{\mathrm{i}}=$ subíndice $i$;

$p s_{1}=$ peso do subíndice $i$;

3 = número de subíndices que compõem o índice geral.

Tabela 2 - Curvas de custos totais das unidades de tratamento e disposição.

\begin{tabular}{l|c|c} 
Tipo de unidade & Investimento inicial (R\$) & Custo de operação (R\$/t) \\
\hline Incineração & $y=5.000^{*} x^{0.8}$ & $y=700^{*} x^{-0.3}$ \\
\hline Triagem semi-mecanizada & $y=1.500^{*} x^{0.8}$ & $y=4.000^{*} x^{-0.4}$ \\
\hline Digestão anaeróbia & $y=34.500^{*} x^{0.55}$ & $y=17.000^{*} x^{-0.6}$ \\
\hline Compostagem & $y=2.000^{*} x^{0.8}$ & $y=2.000^{*} x^{-0.5}$ \\
\hline Aterro sanitário & $y=3.500^{*} x^{0.7}$ & $2.500 \leq x \leq 250.000$ \\
\hline
\end{tabular}

Fonte: Adaptado de Tsilemou \& Panagiotakopoulos (2005) 


\section{Estudo de caso: município de Porto Alegre (RS)}

Porto Alegre é capital do estado do Rio Grande Sul, com população de 1.413.094 habitantes em 2011 (IBGE, 2012). O sistema de gerenciamento do município de Porto Alegre foi utilizado como base para a presente pesquisa, em função de sua atualidade e também pela quantidade e qualidade dos dados e informações disponíveis. O cenário Base foi a situação do gerenciamento de resíduos no município de Porto Alegre no ano de 2011.

Os tipos e as quantidades dos resíduos que fazem parte dos aqui definidos como resíduos sólidos urbanos estão apresentados na Tabela 3. Estão excluídos dos RSU os resíduos públicos de varrição, os resíduos da construção (RCC) e os resíduos especiais (lâmpadas, pilhas e baterias, pneus, entre outros).

Tabela 3 - Quantitativos de resíduos sólidos urbanos em Porto Alegre, em 2011.

\begin{tabular}{l|c|c}
\multirow{2}{*}{ Tipo de resíduo/coleta } & \multicolumn{2}{|c}{ Massa } \\
\cline { 2 - 3 } Resíduo domiciliar coleta convencional & $\mathbf{t} / \mathrm{d}$ & $\mathrm{t} / \mathrm{a}$ \\
\hline Resíduo domiciliar coleta conteinerizada & 120,0 & $281.875,6$ \\
\hline Resíduo domiciliar coleta seletiva & 100,3 & $37.560,0$ \\
\hline Resíduo comercial & 121,0 & $37.391,3$ \\
\hline Resíduo de serviços de saúde (Grupo D) & 19,5 & $6.103,5$ \\
\hline Resíduo de restos de madeira & 7,0 & $2.191,0$ \\
\hline Resíduo verde (podas) & 30,7 & $9.609,1$ \\
\hline Resíduo orgânico - suinocultura & 11,0 & $3.443,0$ \\
\hline Total de resíduos sólidos urbanos & 1.310 & 410.047 \\
\hline
\end{tabular}

Fonte: DMLU (2012)
Os sistemas de coleta de resíduos incluem a coleta domiciliar convencional, que é a coleta dos resíduos domiciliares no sistema porta-a-porta por caminhões coletores de carga traseira e utilização de uma equipe de três garis em cada equipamento. Desde o ano de 2010 também há a coleta conteinerizada dos resíduos domiciliares convencionais. A coleta seletiva, que atende a $100 \%$ dos bairros da cidade, é feita com caminhões de carroceria, sem compactação. A coleta dos demais resíduos é feita em veículos com ou sem compactação.

Como unidades de pré-tratamento ou de tratamento, há 17 unidades de triagem de resíduos seletivos, que são operados de forma independente por diferentes associações de catadores ou de triadores. Há ainda uma unidade de triagem e compostagem que recebe os resíduos misturados é feita a separação dos recicláveis e rejeitos em triagem manual em esteira. Existe também um pátio de compostagem em leiras a céu aberto. Não há presença de formas mais avançadas de tratamento em Porto Alegre, como compostagem acelerada, digestão anaeróbia ou incineração. Sabe-se que $91,7 \%$ da massa de resíduos ainda são enviados para aterro sanitário. Esse aterro sanitário é privado e fica a uma distância de cerca de $110 \mathrm{~km}$ de Porto Alegre, sendo um aterro que tem queima central do biogás e o tratamento dos lixiviados.

Na Figura 1 é apresentado o resultado de composição gravimétrica dos RSU provenientes da coleta domiciliar regular e da coleta seletiva de Porto Alegre.

\section{RESULTADOS E DISCUSSÃO Cenários}

Ao todo foram construídos oito cenários para avaliação. Um é o Cenário BASE, doravante denominado de cenário \#1 BASE (que é o cenário atual de gerenciamento de resíduos de Porto Alegre), e os outros sete foram

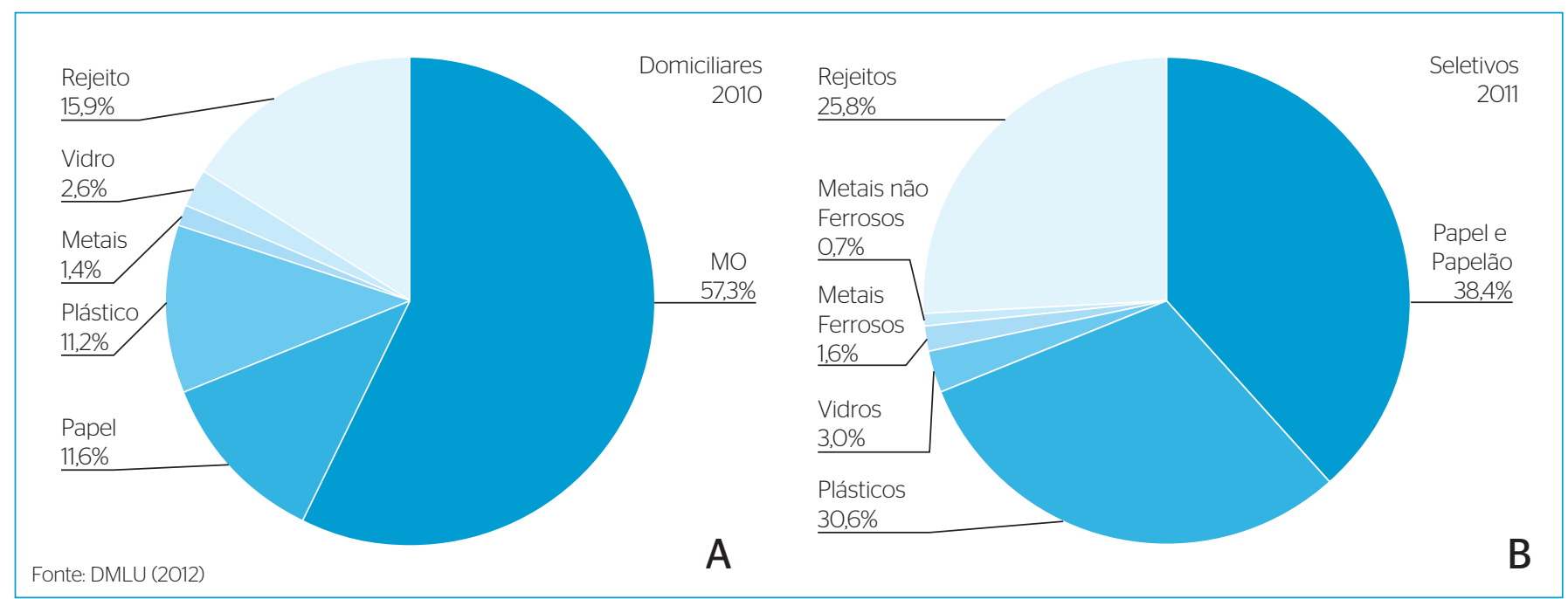

Figura 1 - Composição gravimétrica úmida dos resíduos de Porto Alegre, base 2011. (A) resíduos da coleta domiciliar convencional, (B) resíduos da coleta seletiva. 
construídos a partir das contribuições dos atores sociais. Na Tabela 4 apresenta-se a listagem dos cenários com sua descrição resumida e a responsabilidade pela sua construção. Na Tabela 5 apresenta-se um resumo da sistematização dos oito cenários avaliados

\section{Inventário do ciclo de vida}

Na Tabela 6 é mostrado um resumo do inventário destas emissões totais para todos os cenários.

Os valores são mostrados em gramas (g), sendo que um valor positivo indica uma emissão de fato ao ambiente, ou seja, uma carga ambiental; um valor negativo indica que para aquele cenário e para aquela substância específica a massa deixou de ser emitida ao ambiente, através da reciclagem ou dos processos de tratamento, significando um benefício ambiental.

O programa IWM-2 também faz o inventário energético, em termos de uso, de geração e de economia de energia nas diferentes etapas do sistema de gerenciamento de RSU. Os resultados desse inventário, por cenário, estão apresentados na Tabela 7. Os valores são apresentados em GJ (giga Joule), sendo que valores positivos indicam consumo de energia e valores negativos indicam que houve geração líquida ou economia de energia na etapa e no cenário.

As receitas advindas da comercialização de matérias recicláveis, composto e energia elétrica gerada constam da Tabela 8 .

Tabela 4 - Identificação dos cenários avaliados.

\begin{tabular}{c|c|c} 
Cenário & Descrição básica do cenário & Quem construiu? \\
\#1 BASE & Base ou atual de Porto Alegre, relativo ao ano 2O11 & Existente \\
\hline \#2 PGTA & Provável geral com participação de todos os atores & Todos \\
\hline \#3 PDT & Provável Atores do DMLU & DMLU \\
\hline \#4 OGTA & Otimista geral com participação de todos os atores & Todos \\
\hline \#5 ODT & Otimista Atores do DMLU & Autor \\
\hline \#6 DASI & Ênfase para a digestão anaeróbia sem ênfase à coleta diferenciada & Autor \\
\hline$\# 7$ QM & Ênfase para queima mássica (incineração) com coleta diferenciada & Autor \\
\hline \#8 GICl & Ênfase para coleta diferenciada e o gerenciamento integrado & \\
\hline
\end{tabular}

Obs: DMLU: Departamento Municipal de Limpeza Urbana de Porto Alegre.

Tabela 5 - Fluxo de massa dos oito cenários avaliados.

\begin{tabular}{|c|c|c|c|c|c|c|c|c|c|c|c|c|c|}
\hline \multirow[b]{3}{*}{ 은 } & \multirow{2}{*}{\multicolumn{4}{|c|}{$\begin{array}{l}\text { Por tipo de coleta } \\
\text { (\% em massa) }\end{array}$}} & \multicolumn{6}{|c|}{ Por tipo de tratamento $(\mathrm{t} / \mathrm{d})$} & \multirow{2}{*}{\multicolumn{3}{|c|}{$\begin{array}{l}\text { Destinação final } \\
\text { (\% em massa) }\end{array}$}} \\
\hline & & & & & \multicolumn{2}{|c|}{ Triagem } & \multicolumn{2}{|c|}{ Trat. biológico } & \multicolumn{2}{|c|}{ Trat. térmico } & & & \\
\hline & 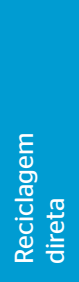 & 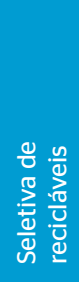 & 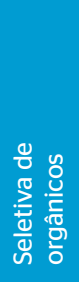 & 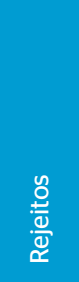 & $\begin{array}{l}\frac{0}{0} \\
\frac{\pi}{0} \\
\frac{1}{0} \\
5 \\
5 \\
1 \\
5 \\
5 \\
\frac{0}{5}\end{array}$ & 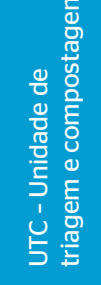 & 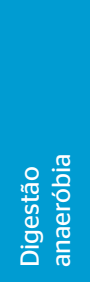 & $\begin{array}{l}E \\
\text { E } \\
\text { Oे } \\
\overline{0} \\
0 \\
0 \\
\text { E } \\
0\end{array}$ & 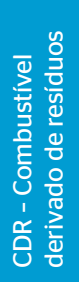 & 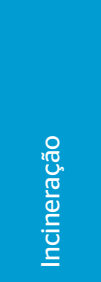 & 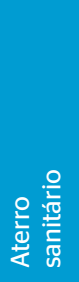 & 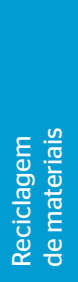 & 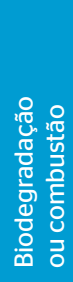 \\
\hline \#1 BASE & 0 & 7,7 & 1,7 & 90,6 & 100,9 & 22,3 & 0,0 & 34,1 & 0,0 & 0,0 & 91,7 & 7,1 & 1,2 \\
\hline \#2 PGTA & 1 & 15 & 10 & 74 & 196,5 & 131,0 & 52,4 & 180,8 & 0,0 & 149,3 & 63,3 & 19,8 & 16,9 \\
\hline \#3 PDT & O & 10 & 3 & 87 & 131,0 & 131,0 & 0,0 & 104,8 & 0,0 & 0,0 & 83,9 & 12,3 & 3,8 \\
\hline \#4 OGTA & 3 & 25 & 38 & 34 & 327,5 & 196,5 & 262,0 & 517,5 & 0,0 & 235,8 & 18,6 & 42,1 & 39,3 \\
\hline \#5 ODT & 2 & 24 & 30 & 44 & 314,4 & 22,7 & 262,0 & 425,8 & 187,3 & 0,0 & 34,5 & 37,4 & 28,1 \\
\hline \#6 DASI & O & 20 & $\mathrm{O}$ & 80 & 262,0 & $1.048,0$ & 524,0 & 366,8 & 0,0 & 0,0 & 38,3 & 36,3 & 24,4 \\
\hline \#7 QM & 0 & 20 & 5 & 75 & 262,0 & 0,0 & 0,0 & 65,5 & 0,0 & $1.053,3$ & 16,1 & 18,0 & 65,9 \\
\hline$\# 8 \mathrm{GICl}$ & O & 25 & 30 & 45 & 327,5 & 0,0 & 393,0 & 275,1 & 0,0 & 685,2 & 10,5 & 29,1 & 60,4 \\
\hline
\end{tabular}


Tabela 6 - Resultados de inventário do ciclo de vida para os cenários avaliados utilizando o programa IWM-2: emissões gasosas e liquidas.

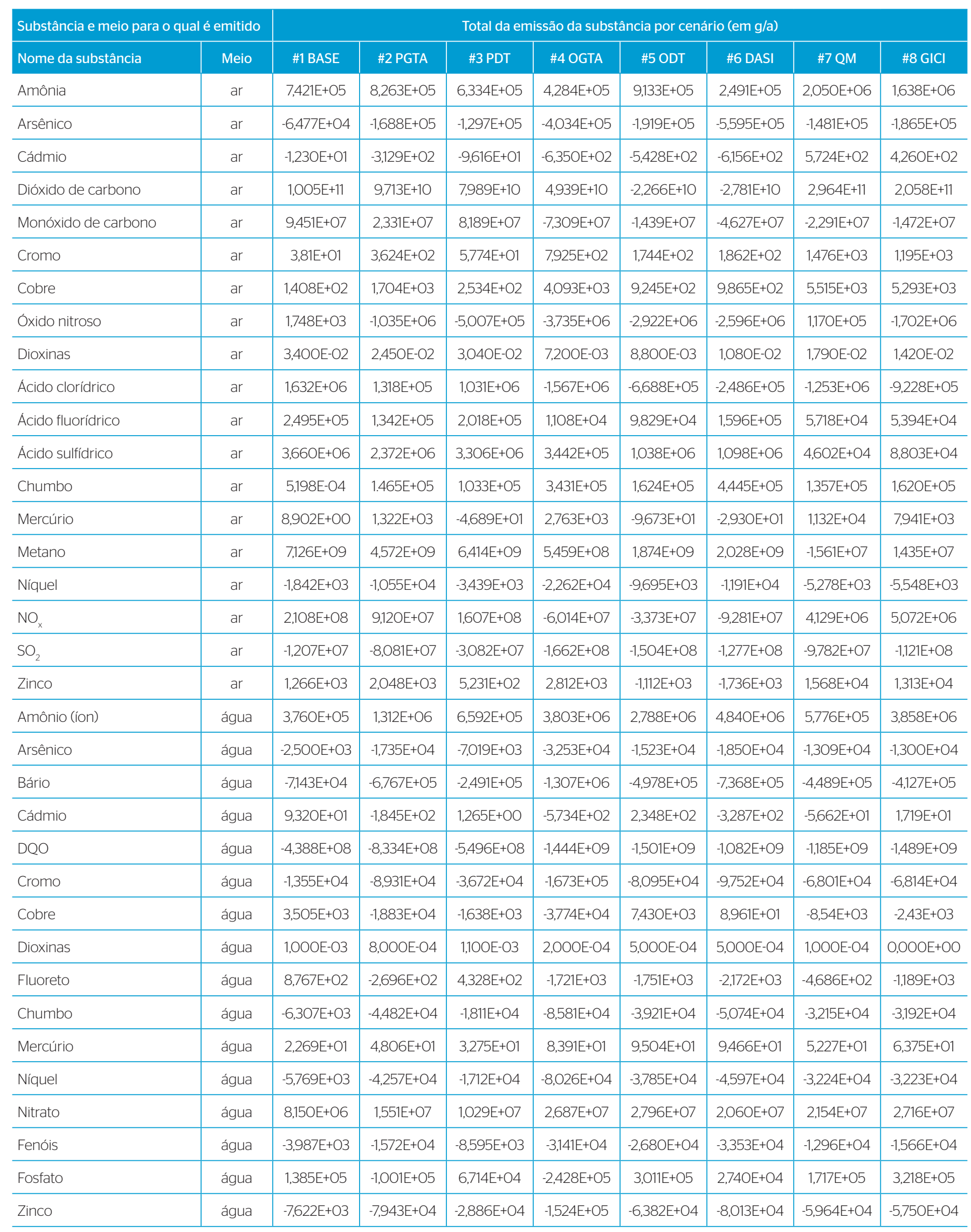

Obs: Valores positivos indicam emissão ao ambiente; valores negativos indicam benefício ambiental. 
O fato de em alguns cenários aparecem valores de receita para a etapa de coleta (Tabela 8) deve-se ao fato do IWM-2 considerar os custos de coleta que deixam de existir nos cenários que tem coleta "por tipo de material" como receita, uma vez que esse fato implica em um menor gasto do órgão público no sistema de coleta. As receitas na etapa aterro sanitário se referem à comercialização da energia elétrica gerada com utilização do biogás. Na etapa reciclagem as receitas (assim como os custos na reciclagem) foram consideradas zero e as receitas da comercialização dos materiais recicláveis aparecem no inventário na etapa triagem.

\section{Avaliação dos impactos de ciclo de vida}

A AICV foi realizada conforme metodologia descrita anteriormente, utilizando indicadores ambientais, econômicos e sociais.

\section{Indicadores ambientais}

Nesta pesquisa, oito indicadores ambientais foram utilizados para a avaliação da sustentabilidade ambiental: mudanças climáticas ( $\mathrm{MuCl})$, toxicidade humana (ToHu), formação de foto-oxidantes (FoFO), acidificação (Acid), eutrofização (Eutr), uso de energia (UsoEn), disposição de recicláveis secos em aterro sanitário (DRecAS) e disposição de recicláveis orgânicos em aterro sanitário (DOrgAS). Os primeiros cinco indicadores listados acima foram calculados através das equações apresentadas por Den Boer et al. (2005a) utilizando os fatores de caracterização da Tabela 1. O valor para o indicador UsoEn, já caracterizado, corresponde ao valor que consta na Tabela 7. Os valores calculados são apresentados na unidade $\mathrm{kg}$ eq/a (quilograma equivalente da substância padrão por ano), com exceção do "uso de energia" que é em GJ/a.

A normalização dos seis indicadores citados no parágrafo anterior foi realizada utilizando os fatores de normalização em nível mundial, para o ano de 1995, apresentados na Tabela 1, resultando em um valor Equivalente Populacional (EP). Os indicadores são apresentados como uma percentagem do impacto ambiental causado em relação à população de Porto Alegre, dividindo o valor do EP pela população total do município.

Tabela 7 - Resultados de inventário do ciclo de vida para as etapas do gerenciamento para os cenários avaliados utilizando o programa IWM-2: uso ou economia de energia.

\begin{tabular}{l|c|c|c|c|c|c|c|c}
\multirow{2}{*}{ Etapa do gerenciamento } & \multicolumn{8}{|c}{ Uso ou economia de energia por etapas do gerenciamento por cenário (em GJ/a) } \\
\cline { 2 - 10 } & \#1 BASE & \#2 PGTA & \#3 PDT & \#4 OGTA & \#5 ODT & \#6 DASI & \#7 QM & \#8 GICI \\
\hline Coleta & 105.841 & 139.204 & 116.665 & 203.675 & 182.175 & 130.671 & 138.394 & 184.985 \\
\hline Triagem & 5.318 & 15.461 & 9.989 & 20.563 & 102.957 & 19.965 & 16.456 & 20.554 \\
\hline Tratamento biológico & 2.608 & 3.689 & 10.379 & -12.768 & -14.529 & -47.863 & 3.979 & -63.238 \\
\hline Tratamento térmico & 0 & -162.418 & 0 & -227.967 & -447.417 & 0 & -750.783 & -540.424 \\
\hline Aterro sanitário & 147.406 & -57.666 & -86.655 & 7.997 & -10.119 & -9.005 & 21.658 & 13.418 \\
\hline Reciclagem & -408.032 & -982.444 & -625.317 & -1.808 .648 & -1.613 .689 & -1.710 .419 & -1.044 .141 & -1.284 .284 \\
\hline Total & -144.459 & -1.039 .171 & -571.619 & -1.808 .111 & -1.792 .095 & -1.608 .747 & -1.608 .140 & -1.661 .118 \\
\hline
\end{tabular}

Obs: Resultados incluem gastos de energia elétrica, combustível (gasolina ou diesel) e gás. Valores de consumo de energia são positivos; valores de economia ou de geração líquida de energia estão em valores negativos.

Tabela 8 - Resultados do inventário do ciclo de vida para as etapas do gerenciamento para os cenários avaliados utilizando o programa IWM-2: receitas de comercialização de subprodutos.

\begin{tabular}{l|c|c|c|c|c|c|c|c}
\multirow{2}{*}{ Receitas de subprodutos } & \multicolumn{6}{|c}{ Receitas de comercialização de subprodutos por etapas do gerenciamento por cenário (em R\$/a) } \\
\cline { 2 - 10 } Coleta & \#1 BASE & \#2 PGTA & \#3 PDT & \#4 OGTA & \#5 ODT & \#6 DASI & \#7 QM & \#8 GICI \\
\hline Triagem & 0 & 2.323 .755 & 0 & 6.882 .291 & 10.681 .944 & 0 & 0 \\
\hline Tratamento biológico & 11.365 .560 & 21.652 .470 & 14.346 .355 & 37.467 .144 & 38.926 .485 & 28.792 .099 & 29.852 .788 & 37.664 .434 \\
\hline Tratamento térmico & 911.165 & 4.922 .824 & 4.720 .390 & 9.235 .222 & 3.154 .315 & 25.387 .878 & 254.900 & 3.025 .589 \\
\hline Aterro sanitário & 0 & 3.783 .837 & 0 & 5.383 .353 & 9.560 .894 & 0 & 18.616 .070 & 13.073 .307 \\
\hline Reciclagem & 0 & 3.375 .636 & 4.709 .223 & 445.255 & 1.385 .177 & 1.509 .339 & 0 & 18.172 \\
\hline Total & 0 & 0 & 0 & 0 & 0 & 0 & 0 \\
\hline
\end{tabular}

Obs:: Resultados incluem receitas da comercialização de subprodutos gerados por cenário, como venda de materiais recicláveis, de composto e energia elétrica (não foi considerada venda de vapor dos processos térmicos). 
Os oito indicadores ambientais são apresentados nas Figuras 2 e 3. O valor de cada indicador está normalizado em termos de EP percentual do impacto ambiental.

$\mathrm{Na}$ Figura 2 apresentam-se seis indicadores ambientais normalizados. Valores positivos indicam que há uma carga ou um dano ambiental, ou seja, há um impacto devido à emissão das substâncias. Valores negativos indicam um "impacto negativo", ou seja, significa que há um benefício ambiental (em função da reciclagem de materiais e energia).

$\mathrm{Na}$ Figura 3 são mostrados os valores comparativos para disposição em aterro sanitário de resíduos ainda com potencial de reciclabilidade. DRecAS mostra a quantidade de resíduos recicláveis secos que são dispostos em aterro em cada cenário e DOrgAS mostra os resíduos orgânicos que vão para aterro mas que poderiam ser reciclados.
Analisando os indicadores ambientais verifica-se que, dos seis indicadores de impactos ambientais, apenas "mudanças climáticas" representa dano ambiental em todos os cenários. É esse indicador que apresenta também o maior dano, chegando até 3\% de todas as emissões de Porto Alegre. Os cenários que mais contribuem com "mudanças climáticas" são os cenários \#7 QM, \#1 BASE, \#3 PDT, \#8 GICI e \#2 PGTA, nessa ordem. Há benefícios ambientais (valores negativos) para os indicadores "toxicidade humana" $\mathrm{e}$ "uso de energia" para todos os cenários avaliados. O melhor desempenho para "toxicidade humana" foi nos cenários \#6 DASI e \#4 OGTA, sendo o pior desempenho o do \#1 BASE (embora ainda represente um benefício ambiental em termos de toxicidade humana). Todos os cenários resultaram em ganho de energia (benefício), com os melhores desempenhos dos cenários \#4 OGTA e \#5 ODT, seguidos logo após pelos \#6 DASI, \#7 QM e \#8 GICI.

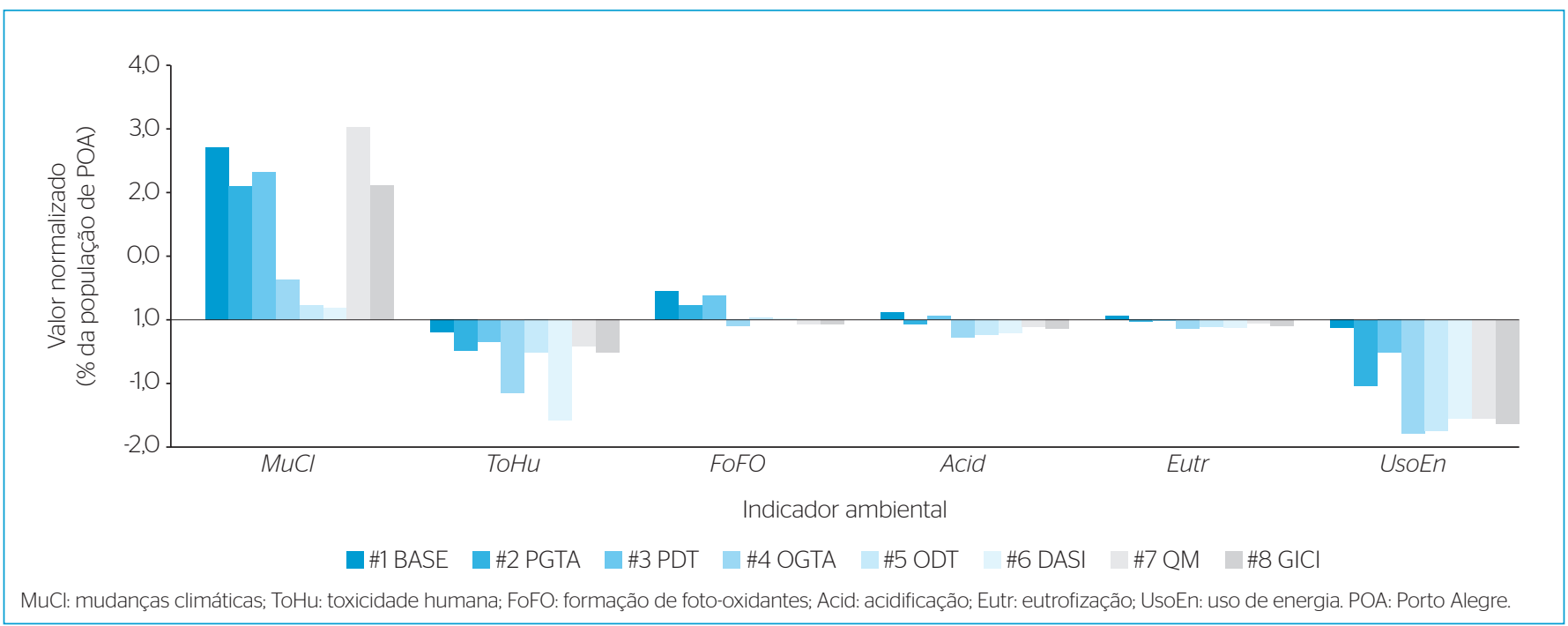

Figura 2 - Indicadores ambientais normalizados: impactos ambientais e uso de energia.

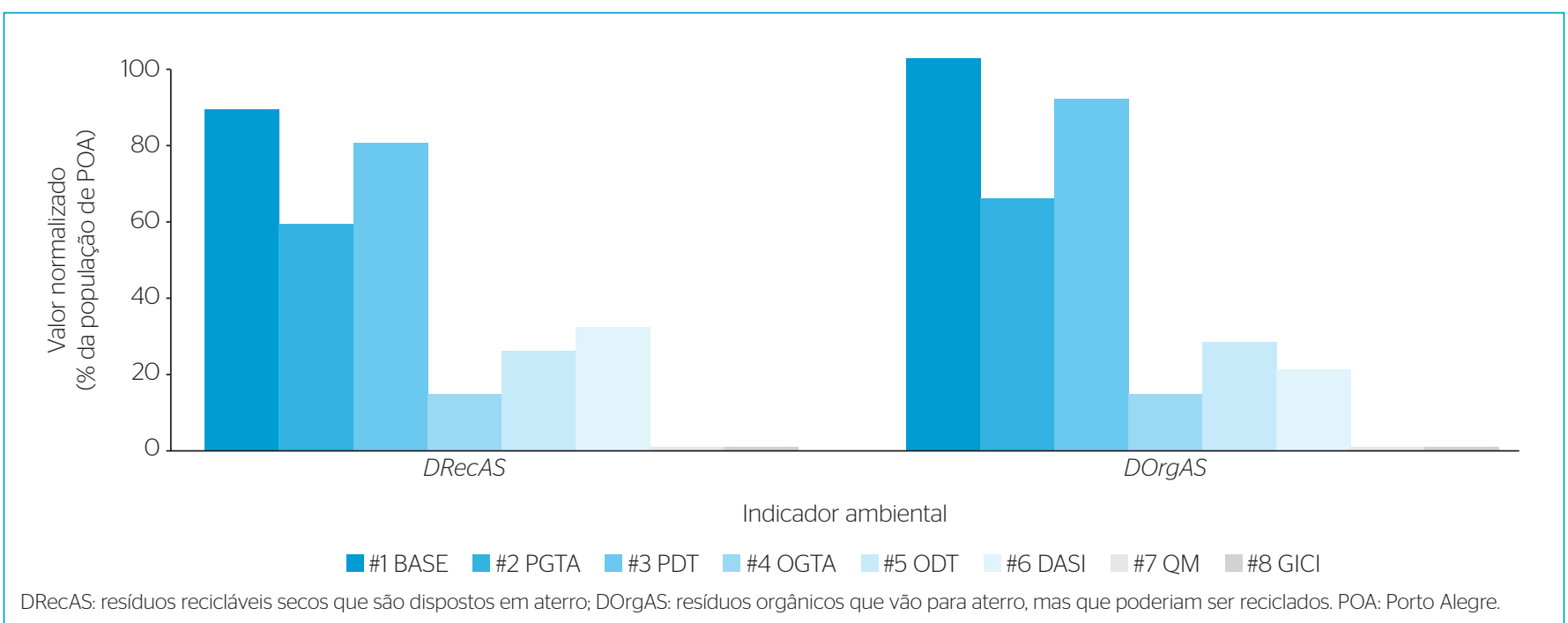

Figura 3 - Indicadores ambientais normalizados: disposição de recicláveis em aterro. 
O indicador "formação de foto-oxidantes" representou um beneficio ambiental nos cenários \#4 OGTA, \#7 QM e \#8 GICI e um dano ambiental para os demais cenários, com os cenários \#1 BASE e \#3 PDT apresentando os piores desempenhos nesse indicador. Os indicadores "acidificação" e "eutrofização" tiverem valores menores comparados aos demais. Nos dois indicadores, nos cenários \# 1 BASE e \#3 PDT houve impacto ou dano ambiental, e nos demais cenários ocorreu benefício ambiental.

Avaliando os indicadores de "disposição de resíduos recicláveis em aterro sanitário", os piores desempenhos foram dos cenários \#1 BASE, \#3 PDT e \#2 PGTA, nessa ordem, com valores disposição de recicláveis potencialmente recicláveis em aterro que vão de 55 a quase $98 \%$. Em uma faixa intermediária, de 13 a 30\% de recicláveis que ainda vão para aterro, situam-se os cenários \#4 OGTA, \#3 ODT e \#6 DASI. Os indicadores estão zerados para os cenários \#7 QM e \#8 GICI, pois em ambos todos os resíduos e rejeitos são encaminhados para incineração, resultando na disposição em aterro sanitário somente de cinzas.

Considerando as metas de redução de disposição de recicláveis em aterro sanitário estabelecidas pelo PNRS (MMA, 2012) - que embora ainda não publicado oficialmente já se encontra uma versão final do Plano na página do MMA —, que é de redução de $60 \%$ (para a região Sul) até 2031 para resíduos recicláveis secos e resíduos orgânicos, tem-se que somente os cenários \#2 PGTA e \#3 PDT não atendem essas metas, sendo que os demais cenários atendem com folga essas metas estabelecidas.

\section{Indicadores econômicos}

Os resultados para os seis indicadores econômicos estão apresentados nas Figuras 4 e 5 . Os custos por tonelada gerenciada variam de $\mathrm{R} \$ 210,52 / \mathrm{t}$ a $\mathrm{R} \$ 267,41 / \mathrm{t}$; os custos anuais por domicílio ficam na faixa de $R \$ 164,94 / \mathrm{dom} \cdot \mathrm{a}$ a $\mathrm{R} \$ 209.51,35 / \mathrm{dom} \cdot \mathrm{a}$ e os custos por pessoa variam de R\$ 61,09/pes·a a 77,60/pes·a. Ordenando os cenários de menor ao maior custo, tem-se o seguinte: \#5 ODT, \#1 BASE, \#6 DASI, \#7 QM, \#3 PDT, \#2 PGTA, \#4 OGTA e \#8 GICI.

O valor "custo líquido" se refere ao custo total do sistema de gerenciamento de resíduos subtraída a receita total anual por comercialização dos subprodutos. Já para o indicador "relação receita e despesa", considerou-se também o valor da receita relativa à "taxa de coleta de resíduos" admitida constante para todos os cenários no valor de $\mathrm{R} \$ 99.561,329,00$ por ano.

Os indicadores "\% do orçamento PMPA" (PMPA significa prefeitura municipal de Porto Alegre) e "\% salário mínimo" seguem exatamente a mesma ordem dos custos unitários acima, sendo que os valores gastos com gerenciamento de RSU variam de 3,6 a 4,6\% do orçamento total da prefeitura de Porto Alegre (salienta-se que nesse valor não estão incluídos os serviços de limpeza urbana), e a porcentagem gasta por pessoa com o sistema de gerenciamento de resíduos sólidos fica na ordem de $1 \%$ do salário mínimo em todos os cenários (variação de 0,83 a 1,06\%).

O comportamento do indicador "relação receita/despesa" foi levemente diferente dos outros cinco indicadores econômicos. No cenário \#7 QM esta relação é igual a 1 e no cenário \#6 DASI, praticamente 1, significando que nesses cenários as receitas (incluindo a "taxa de coleta") se igualam aos custos totais. Nos cenários \#1 BASE e \#5 ODT as receitas chegam a superar em cerca de $10 \%$ as despesas totais. Estes quatro cenários, que são os de menores custos unitários, são autossustentáveis em termos econômicos. Nos demais cenários os custos totais superaram as receitas e a porcentagem varia de 2 a $6 \%$, mostrando que mesmo nesses casos poder-se-ia ajustar a "taxa de coleta" de modo que não houvesse déficit econômico ou financeiro.

\section{Indicadores sociais}

Os indicadores sociais foram calculados com a metodologia apresentada por Den Boer et al. (2005c). Os resultados para os 12 indicadores sociais calculados estão apresentados na Figura 6, com a identificação da etapa à qual o indicador se refere: armazenamento temporário (AT), coleta e transporte (C\&T) e tratamento ( $\mathrm{Tr})$. Todos os indicadores estão normalizados entre 0 (zero) e 1, em que 0 é a melhor situação do ponto de vista social e 1 a pior situação.

Quanto mais junto ao centro do gráfico radar estiverem as linhas para um mesmo indicador, mais perto de zero estará o valor do indicador e menos relevante ou impactante será esse aspecto social. De outra forma, pode-se também fazer a leitura sobre os cenários mais e menos impactantes do ponto de vista social: tomando um mesmo cenário, quanto mais perto do centro estiver a linha desse cenário, menor o impacto deste; e quanto mais para a borda externa do gráfico, maior será o impacto social.

Analisando as informações contidas na Figura 6, pode-se concluir que: - os impactos sociais são muito similares entre os cenários, apresentando pequena variação, com exceção dos indicadores TaRe, QTEm, EsUC(AT);

- os aspectos com pior desempenho foram Odor(Tr) para todos os cenários e TaRe para os cenários \#1 BASE, \#3 PDT e \#2 PGTA;

- os cenários \#1 BASE, \#2 PGTA e \#3 PDT são os de pior desempenho social.

Como os cenários tiveram desempenho social muito parecido na maioria dos aspectos, pela análise da Figura 6, não ficam claros quais são os cenários de melhor desempenho. Em uma análise superficial, no entanto, constata-se no gráfico que os melhores desempenhos são dos cenários \#4 ao \#8. A definição de quais são os melhores cenários do ponto vista social será detalhada no item a seguir, quando se faz a hierarquização dos cenários considerando todos os aspectos da sustentabilidade, por meio do cálculo do índice de sustentabilidade geral. 


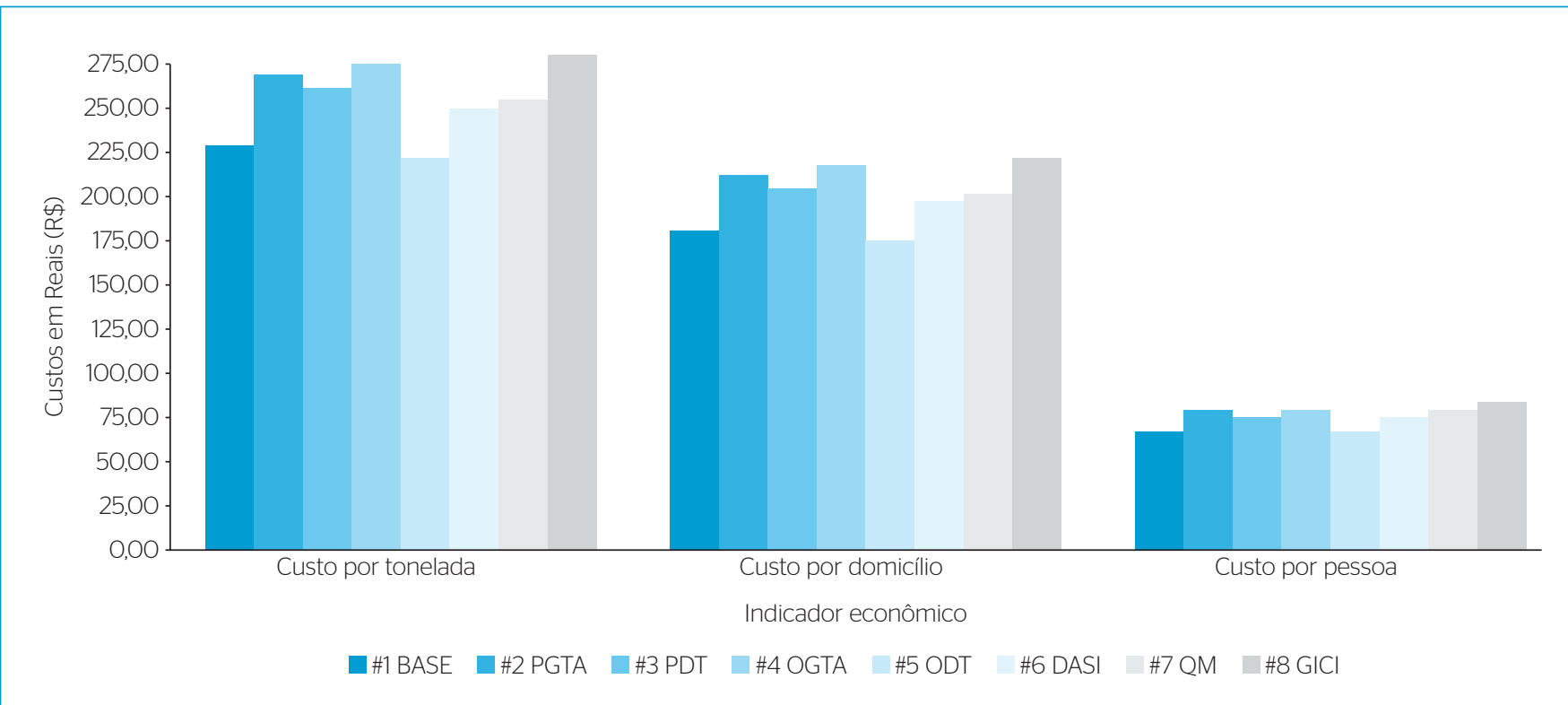

Figura 4 - Indicadores econômicos para os cenários: custos em Reais (R\$).

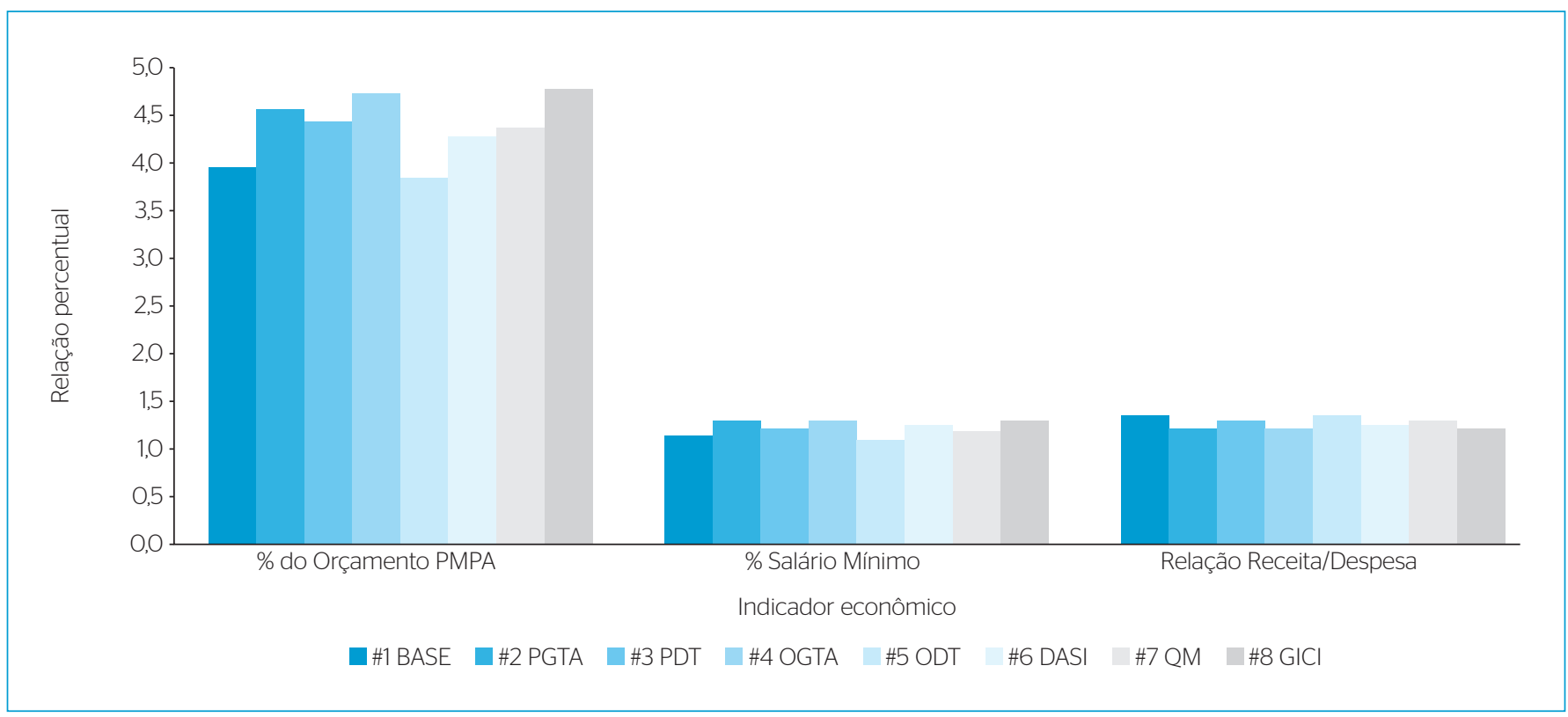

Figura 5 - Indicadores econômicos para os cenários: valores porcentuais dos custos em relação ao orçamento e do salário mínimo, e relação entre receita e despesa.

\section{Hierarquização dos Cenários}

O índice de sustentabilidade geral combina em um único valor (que vai de 0 a 1) os subíndices ambiental, econômico e social (índices calculados conforme Equações 4 e 5). Também no cálculo deste índice geral (Figura 7) foram utilizados os pesos para os aspectos avaliados e uma combinação sem diferenciação de pesos (todos os três com peso 1).

Assim como no caso dos subíndices parciais, os resultados dos valores calculados do índice geral tiveram pouca diferença para as três curvas (pesos DMLU, pesos “Todos Atores” e sem pesos). Nesse caso, entretanto, houve alteração na ordem de sustentabilidade geral dos cenários, sendo que a ordem com pesos DMLU ficou idêntica à ordem sem pesos diferentes para os subíndices (até porque os pesos dos "Atores DMLU” para os subíndices também são iguais entre si).

Conforme pode ser verificado na Figura 7, o índice de sustentabilidade geral da AICV resultou na seguinte ordem (do melhor ao pior desempenho geral), considerando os pesos dos Atores DMLU e sem adoção de pesos (todos subíndices com peso 1): - 1º: \#5 ODT (cenário otimista construído pelos atores DMLU); 


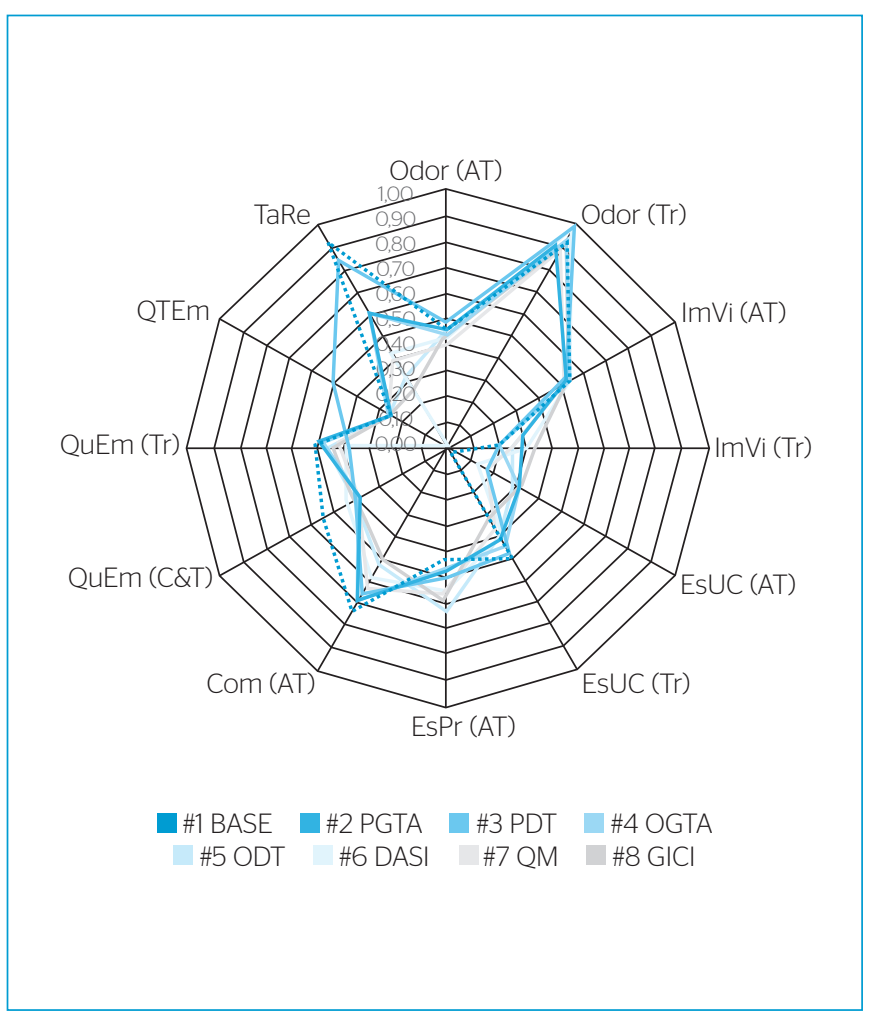

Figura 6 - Indicadores sociais normalizados para os cenários: todos indicadores.

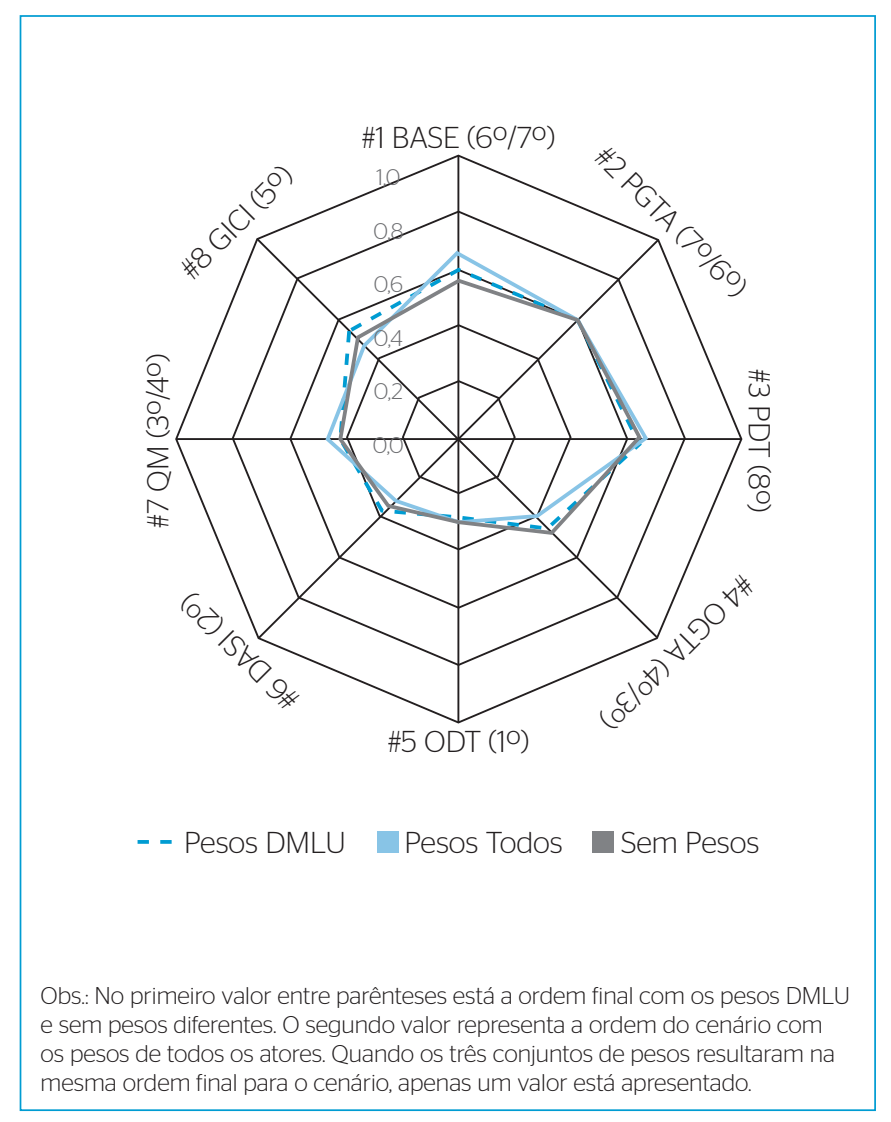

Figura 7 - Índices de sustentabilidade geral por cenário.
- $\quad 2^{\circ}$ : \#6 DASI (cenário com biodigestão construído pelo autor);

- $\quad 3^{\circ}$ : \#7 QM (cenário queima mássica construído pelo autor);

- $\quad 4^{\circ}$ : \#4 OGTA (cenário otimista construído por todos os atores);

- $\quad 5^{\circ}$ : \#8 GICI (cenário gerenciamento integrado construído pelo autor);

- $\quad 6^{\circ}$ : \#1 BASE (cenário atual);

- 7º: \#2 PGTA (cenário pessimista construído por todos os atores);

- $\quad 8^{\circ}$ : \#3 PDT (cenário pessimista construído pelos atores DMLU).

Considerando os pesos atribuídos pelo grupo "Todos os Atores”, há inversão na ordem geral em dois casos: o cenário \#4 OGTA passa a ser o terceiro e o \#7 QM para quarto, e o \#2 PGTA fica em sexto, passando o cenário \#1 BASE para sétimo.

Como pode ser visualizado na Figura 7, o cenário \#5 ODT é destacadamente o cenário mais sustentável em qualquer combinação de pesos dos subíndices. Em seguida vêm três cenários com desempenho geral similar entre si: \#6 DASI, \#7 QM e \#4 OGTA. O cenário \#8 GICI teve um desempenho intermediário, e os cenários com pior desempenho (e com similaridade de pontuação entre eles) foram o \#2 PGTA, \#1 BASE e \#3 PDT.

Os cenários otimistas construídos com a participação dos atores sociais ficaram entre os quatro cenários de melhor desempenho no índice de sustentabilidade geral, sendo que o primeiro colocado foi o cenário otimista construído pelos atores do DMLU (\#5 ODT), tendo o cenário construído com a participação de todos os atores (\#4 OGTA) ficado em terceiro lugar com adoção dos pesos de "Todos os Atores", e em quarto com as outras duas combinações de pesos.

\section{CONCLUSÕES}

Com base nos resultados obtidos na pesquisa, as seguintes conclusões podem ser postuladas:

a) Os cenários construídos pela participação de atores sociais de fora do DMLU, em comparação aos cenários construídos com a opinião dos atores do DMLU, apresentaram maior nível de coleta diferenciada, maior coberta da coleta automatizada (conteinerizada) para os resíduos seletivos, maior participação do processo de compostagem como forma de tratamento, e um menor envio de resíduos (rejeitos) para aterro sanitário;

b) A utilização de programas computacionais na etapa de inventário de ciclo de vida, apesar de necessitar de um grande número de dados e de informações para a sua alimentação, se mostrou viável para apoio à decisão para a definição de sistemas integrados e sustentáveis de gerenciamento de resíduos urbanos;

c) O cenário construído com a visão otimista dos atores do DMLU foi o que apresentou o menor custo unitário líquido final, evidenciando a preocupação dos técnicos e dos gestores do órgão municipal com os aspectos da sustentabilidade financeira; 
d) Os cenários apresentaram desempenho similar para o subíndice de sustentabilidade social, sendo que o pior desempenho social foi do cenário atual. Os melhores desempenhos nos aspectos sociais foram dos cenários construídos com a participação dos atores sociais (tanto do DMLU como de todos os atores), juntamente com o cenário com forte participação da digestão anaeróbia;

e) A adoção do índice de sustentabilidade geral se mostrou eficiente para a hierarquização final da sustentabilidade dos cenários, utilizando a ponderação dos subíndices (ambiental, econômico e social) com os pesos definidos com a participação dos atores convidados;

f) A aplicação da metodologia proposta pela pesquisa ao sistema de gerenciamento de resíduos urbanos da cidade Porto Alegre, com base nos indicadores de sustentabilidade geral, resultou em que o cenário mais sustentável foi o construído pelos atores DMLU, mostrando uma visão apurada dos técnicos do município em relação a modelos de gerenciamento de RSU; g) Por fim, pode-se concluir que a utilização de processos estruturados de apoio à decisão, adotando cenários futuros construídos com participação de atores sociais e avaliados por meio da aplicação de técnicas de avaliação de ciclo de vida e de indicadores de sustentabilidade, permite a definição de alternativas e modelos de gerenciamento de RSU que atendam aos preceitos da Política Nacional de Resíduos Sólidos, em especial no que tange à maximização da reciclagem com envio para aterro sanitário apenas dos rejeitos.

\section{AGRADECIMENTOS}

Os autores gostariam de agradecer ao departamento municipal de limpeza urbana (DMLU) de Porto Alegre, Rio Grande do Sul, pela disponibilização de todos os dados e informações sobre o sistema de gerenciamento de resíduos dessa cidade, sem os quais a realização desse trabalho não teria sido possível.

\section{REFERÊNCIAS}

ABNT - Associação Brasileira De Normas Técnicas. (2009) Gestão ambiental - Avaliação do ciclo de vida - Requisitos e orientações. NBR ISO 14.044. Rio de Janeiro: ABNT. 17 p.

BRASIL. (2010) Política Nacional de Resíduos Sólidos. Lei n 12.305, de 2 de agosto de 2010. Institui a Política Nacional de Resíduos Sólidos; altera a Lei 9.605, de 12 de fevereiro de 1998; e dá outras providências. Diário Oficial da União; 2010. Seção 1.

DEN BOER, E.; DEN BOER. J.; BERGER, J.; JAGER, J. (2005a) Waste management planning and optimization: handbook of municipal waste prognosis and sustainability assessment of waste management systems. Stuttgart: Ibidem-Verlart. 306 p.

DEN BOER, E;; DEN BOER. J.; JAGER, J.; RODRIGO, J.; MENESES, M.; CASTELLS, J. et al. (2005b) Deliverable report on D3.1 and D3.2: environmental sustainability criteria and indicators for waste management (work package 3). Darmstadt: Technishe Universitaet Darmstadt. 183 p.

DEN BOER, E.; DEN BOER. J.; BERGER, J.; JAGER, J.; RODRIGO, J.; MENESES, M. et al. (2005c) Deliverable report on D5.1 and D5.2: social sustainability criteria and indicators for waste management (work package 5). Darmstadt: Technishe Universitaet Darmstadt. 198 p.

DMLU - Departamento Municipal de Limpeza Urbana de Porto Alegre. (2011) Execução orçamentária de 2010. (Não publicado).

DMLU - Departamento Municipal de Limpeza Urbana de Porto Alegre. (2012) Relatórios gerenciais internos. (Não publicado).

GUINÉE, J.B.; GORRÉE, M.; HEIJUNGS, R.; HUPPES, G.; KLEIJN, R.; KONING, A. et al. (2001) Handbook on life cycle assessment: an operational guide to the ISO standards. Dordrecht: Kluver Academic Publishers. 692 p.

IBGE - Instituto Brasileiro de Geografia e Estatística. (2010) Pesquisa Nacional de Saneamento Básico - PNSB. Rio de Janeiro: IBGE.
IBGE - Instituto Brasileiro de Geografia e Estatística. (2012) Estimativa populacional. Rio de Janeiro: IBGE. Disponível em: <www.ibge.gov.br>. Acessado em: 20 jun. 2012.

IPES - Promoción del Desarrollo Sostenible \& BID - Banco Interamericano de Desarollo. (2005) Mejoramiente de las condiciones de vida de recicladores informales de ALC. 244 p. Disponível em: $<$ www.oit.org.ar/portal/programa-cea/index.php?option=com_conten t\&view=article\&id=110:mejoramiento-de-las-condiciones-de-vida-derecicladores-informales-en-alc-atnnp-8779-rs-bg\&catid=8:empleo-yempleabilidad-\&ltemid=24>. Acessado em: 2 jul. 2011.

JOOS, W.; CARABIAS, V:; WINISTOERFER, H.; STUECHELI, A. (1999) Social aspects of public waste management in Switzerland. Waste Management, v. 19, p. 417-425.

KUHN, T.S. (2003) A estrutura das revoluções científicas. 7 ed. São Paulo: Perspectiva. $262 \mathrm{p}$.

MCDOUGALL, F.R.; WHITE, P.R.; FRANKE, M.; HINDLE, P. (2001) Integrated solid waste management: a life cycle inventory. 2 ed. Oxford: Blacwell Science Ltd. 513 p.

MMA - Ministério do Meio Ambiente. (2012) Plano Nacional de Resíduos Sólidos. Brasília: MMA (Verão preliminar) 106 p.

TSILEMOU, K: PANAGIOTAKOPOULOS, D. (2005) Deliverable report on D4.1 and D4.2: economic sustainability criteria and indicators for waste management (work package 4). Xanthi: Democritus University Thrace. 77 p.

WHITE, P.R:; FRANKE, M:; HANDLE, P. (1995) Integrated solid waste management: a life cycle inventory. Gaithersburg: Aspen Publishers Inc. 362 p.

WILSON, E.J.; MCDOUGALL, F.R.; WILLMORE, J. (2001) Euro-trash: searching for a more sustainable approach to waste management. Resources, Conservation and Recycling, v. 31, p. 327-346. 